\title{
The coverage of continuum of care in maternal, newborn and child health: a cross-sectional study of woman-child pairs in Ghana
}

\author{
Akira Shibanuma, ${ }^{1}$ Francis Yeji, ${ }^{2}$ Sumiyo Okawa, ${ }^{1}$ Emmanuel Mahama, ${ }^{3}$ \\ Kimiyo Kikuchi, ${ }^{1}$ Clement Narh, ${ }^{4,5}$ Yeetey Enuameh, ${ }^{3}$ Keiko Nanishi, ${ }^{1}$ \\ Abraham Oduro, ${ }^{2}$ Seth Owusu-Agyei, ${ }^{3}$ Margaret Gyapong, ${ }^{4}$ Gloria Quansah Asare, ${ }^{6}$ \\ Junko Yasuoka, ${ }^{1,7}$ Evelyn Korkor Ansah, ${ }^{6,8}$ Abraham Hodgson, ${ }^{6}$ Masamine Jimba, ${ }^{1}$ \\ the Ghana EMBRACE Implementation Research Project Team
}

\begin{abstract}
To cite: Shibanuma A, Yeji $F$, Okawa $\mathrm{S}$, et al. The coverage of continuum of care in maternal, newborn and child health: a cross-sectional study of woman-child pairs in Ghana. BMJ Glob Health 2018;3:e000786. doi:10.1136/ bmjgh-2018-000786
\end{abstract}

Handling editor Valery Ridde

Received 20 February 2018 Revised 18 May 2018 Accepted 9 June 2018

\section{Check for updates}

(c) Author(s) (or their employer(s)) 2018. Re-use permitted under CC BY-NC. No commercial re-use. See rights and permissions. Published by BMJ.

For numbered affiliations see end of article.

Correspondence to Dr Masamine Jimba; mjimba@m.u-tokyo.ac.jp

\section{ABSTRACT}

Introduction The continuum of care has recently received attention in maternal, newborn and child health. It can be an effective policy framework to ensure that every woman and child receives timely and appropriate services throughout the continuum. However, a commonly used measurement does not evaluate if a pair of woman and child complies with the continuum of care. This study assessed the continuum of care based on two measurements: continuous visits to health facilities (measurement 1) and receiving key components of services (measurement 2). It also explored individual-level and area-level factors associated with the continuum of care achievement and then investigated how the continuum of care differed across areas.

Methods In this cross-sectional study in Ghana in 2013, the continuum of care achievement and other characteristics of 1401 pairs of randomly selected women and children were collected. Multilevel logistic regression was used to estimate the factors associated with the continuum of care and its divergence across 22 areas.

Results Throughout the pregnancy, delivery and postdelivery stages, $7.9 \%$ of women and children achieved the continuum of care through continuous visits to health facilities (measurement 1). Meanwhile, 10.3\% achieved the continuum of care by receiving all key components of maternal, newborn and child health services (measurement 2). Only $1.8 \%$ of them achieved it under both measurements. Women and children from wealthier households were more likely to achieve the continuum of care under both measurements. Women's education and complications were associated with higher continuum of care services-based achievement. Variance of a random intercept was larger in the continuum of care servicesbased model than the visit-based model.

Conclusions Most women and children failed to achieve the continuum of care in maternal, newborn and child health. Those who consistently visited health facilities did not necessarily receive key components of services.

\section{Key questions}

What is already known?

- Women and children do not necessarily receive all recommended care along the continuum of care from pregnancy to post-delivery.

What are the new findings?

- From pregnancy to post-delivery, $10 \%$ of the pairs of women and children received all recommended components of services, and $2 \%$ of them received them in addition to meeting the recommended number of visits to health facilities in Ghana.

- Geographical disparity existed in the coverage of the continuum of care in Ghana.

What do the new findings imply?

- Health administrators should ensure that women and children receive all the key components of services on their visit to health facilities.

- Continuum of care should be measured at the individual level and compared subnationally to reduce inequality in provision of care across subnational areas.

\section{INTRODUCTION}

Saving lives from maternal and neonatal complications remains a major health challenge in low-income and middle-income countries. In these countries, the maternal mortality ratio was 20 times higher and the neonatal mortality rate was 7 times higher than those in high-income countries in 2015. ${ }^{12}$ Many such deaths are preventable by receiving appropriate care for maternal, newborn and child health (MNCH) ${ }^{3-6}$ This also contributes to their long-term health outcomes. ${ }^{7}$

The coverage of $\mathrm{MNCH}$ services is typically measured as the number of antenatal 
care (ANC) visits, delivery attended by a skilled birth attendant (SBA) and the number of postnatal care (PNC) visits. The coverage has been improving in low-income and middle-income countries, and it is regarded as one of the major contributions to the reduction of maternal, newborn and child mortalities. ${ }^{8}$ However, targeting the coverage of each $\mathrm{MNCH}$ service separately does not necessarily ensure that every woman and her child receives a series of $\mathrm{MNCH}$ services continuously from the pregnancy to post-delivery stages. ${ }^{9}$

The continuum of care (CoC) has recently received attention in $\mathrm{MNCH}$; its intention is to guarantee that every woman and child receives care whenever they need. CoC can be an effective policy framework to improve the coverage of MNCH services for women and children. ${ }^{10-14}$ It is broadly divided into two dimensions: time and space. $\mathrm{CoC}$ at the time dimension refers to a situation where a woman and her child receive $\mathrm{MNCH}$ services from prepregnancy to childhood. CoC at the space dimension addresses coordination among family level, community-level and facility-level MNCH care and referral to advanced-level care if needed. ${ }^{10} \mathrm{CoC}$ at the space dimension is an important concept for those who need specific care for their complications, danger signs and diseases. In contrast, $\mathrm{CoC}$ at the time dimension is a policy goal that every woman and child should achieve. Thus, it can be an indicator that measures the coverage of $\mathrm{MNCH}$ services.

$\mathrm{CoC}$ at the time dimension addresses the importance of linkages among the packages of MNCH service delivery at different reproductive stages. ${ }^{3} 1012$ Among such packages, routine ANC, delivery attended by SBA and PNC are primary means of ensuring CoC. Women and children can potentially receive timely and necessary $\mathrm{MNCH}$ care through these packages and reduce risks of maternal and infant mortality and morbidity. However, only $8 \%$ of women and children in Ghana received all of ANC four times or more, delivered attended by SBA and PNC three times. ${ }^{15}$ In Pakistan, $27 \%$ of women and children received all of ANC four times or more, delivered attended by SBA and PNC at least once within 6 weeks of delivery in 2012$2013{ }^{16}$ In nine South Asian and sub-Saharan African countries, $17 \%$ of women and children received all of ANC four times or more, delivered attended by SBA and the first PNC within 24 hours of delivery. ${ }^{17}$ These CoC coverage are lower than composite coverage index, the weighted average of individual MNCH indicators. ${ }^{18} 19$ That is, improvement in individual $\mathrm{MNCH}$ indicators does not necessarily translate into a situation that no one is left behind from receiving all essential MNCH services.

Achieving $\mathrm{CoC}$ in $\mathrm{MNCH}$ at the time dimension may be measured differently. It can be measured as the components of services that mothers and children receive at ANC, delivery attended by SBA and PNC. In low-income and middle-income countries, some of the key components are not provided in ANC..$^{20-24}$ This lack of key components in service delivery is also referred to as the quality gap in CoC in MNCH. ${ }^{24}{ }^{25}$ Similar problems exist in delivery ${ }^{5426}$ and PNC. ${ }^{27}{ }^{28}$ Under the quality gap, even if women and children visit health facilities with their own intentions, they may not receive some components of services due to the lack of services available at health facilities. Thus, CoC could be more affected by services provided by a health facility when it is measured as receiving key components of services, rather than simply counting the number of visits. Such health facility factors may explain part of availability of $\mathrm{MNCH}$ services and efficiency in managing health workers and services at health facilities. ${ }^{29}$ In addition to such supplyside factors, CoC can be influenced by factors related to women and their households. According to an analysis in Cambodia among women who received ANC and delivered attended by SBA, women from wealthier households tended to receive PNC more. ${ }^{30}$ A study in Ghana showed that marital status, education, means of transportation to a health facility, women's autonomy in decision making and wealth level were associated with achieving CoC. ${ }^{15}$

Ghana is one of the sub-Saharan African countries to improve MNCH-related health outcomes, although there is much to be done to meet the global target of such outcomes. ${ }^{19}{ }^{31-33}$ The maternal mortality ratio and infant mortality rate in Ghana were estimated at 380 per 100000 live births in 2013 and 49 per 1000 live births, respectively, in 2012. ${ }^{34}$ Improved coverage of ANC, delivery attended by SBA and PNC have been regarded as keys to improving MNCH-related health outcomes. ${ }^{35-38}$ The ANC coverage of four times or more visits was $87.3 \%$, delivery attended by SBA was $73.7 \%$ and first postnatal check-up for mothers within 48 hours was $81.1 \%$, according to the Demographic and Health Survey (DHS) $2014 .^{31}$ However, such coverage differed across 10 regions of Ghana. For example, the coverage of delivery attended by SBA ranged from $36.4 \%$ in the lowest region to $92.1 \%$ in the highest region. ${ }^{31}$ Room for improvement exists in MNCH service delivery in Ghana.

The objectives of this study were threefold. First, this study compared CoC achievement in $\mathrm{MNCH}$ at the time dimension based on two measurements: CoC measured by counting visits and $\mathrm{CoC}$ measured by key components of services that were received. Second, this study compared the factors affecting CoC based on the two different $\mathrm{CoC}$ measurements. Finally, this study examined to what extent $\mathrm{CoC}$ achievement was different across areas, using the two measurements described above.

\section{METHODS \\ Study design and area}

Under a cross-sectional design, this study measured MNCH service-seeking behaviours of women and their children at the pregnancy, delivery and post-delivery stages in Ghana. It also measured their background characteristics and complications using face-to-face interviews with women in health demographic surveillance sites under three Health Research Centres (HRC) in Ghana, namely Dodowa, ${ }^{39}$ Kintampo ${ }^{40}$ and Navrongo. ${ }^{41}$ The total 
population of this survey area was 456492 in 2012 and the estimated number of live births per year was 13695 , assuming that the crude birth rate was 30 out of 1000 people.

This study was conducted as part of the formative research of the Ghana EMBRACE (Ensure Mothers and Babies Regular Access to Care) Implementation Research. ${ }^{42}$ This research is aimed at evaluating the impact and implementation process of a set of $\mathrm{MNCH}$ interventions that enhance CoC under the EMBRACE Model, as proposed by the Government of Japan. ${ }^{434}$ It was funded by the Japan International Cooperation Agency (JICA) and the JICA Research Institute.

\section{Participants and selection criteria}

The targeted women in this study were aged between 15 and 49 years who experienced their latest pregnancy as a live birth or stillbirth between January 2011 and April 2013. Inclusion criteria were women who lived in study site on the date of the data collection. If the women delivered twice or more during the above period, the latest pregnancy data were used.

A total of 1500 women were selected based on the two-stage random sampling method. The primary sampling unit involved communities under a zone or subdistrict (area), depending on HRC. The study site has 22 areas in three HRCs. Women were randomly selected under probability proportional to the sample size. The sample size was calculated based on the assumption that the expected coverage of key MNCH services throughout pregnancy, delivery and post-delivery was $15 \%$. A sample size of 1275 provided an estimate with $2 \%$ confidence limits at a 0.05 significance level. Assuming $15 \%$ of women with incomplete information, a total of 1500 women was proposed.

\section{Measurements}

Two outcome variables were used to assess CoC achievement in $\mathrm{MNCH}$. The first measurement is the proportion of women and children who received $\mathrm{MNCH}$ services at the pregnancy, delivery and post-delivery stages. Under this measurement, a pair (woman and child) achieved the CoC when the woman received ANC four times or more, delivered at a health facility and received both maternal and child PNC within 48 hours and around 2 and 6 weeks post-delivery. According to our observations in the study site, women and children visited health facilities and received such $\mathrm{MNCH}$ services while few received them at the community level. Thus, coverage under the first measurement is referred to as 'visit-based CoC'. The second measurement is the proportion of women and children who received the key components of $\mathrm{MNCH}$ services during ANC and PNC, and during and post-delivery based on women's self-reports. Coverage under the second measurement is referred to as 'services-based CoC'.

The components of MNCH services were measured in this study as follows. As services received during
ANC, three components of the services were measured: received immunisation for tetanus toxoid, received intermittent preventive treatment, and received an HIV test. For delivery, two components of the services were measured: exercised skin-to-skin care immediately after delivery and initiated breast feeding within an hour of delivery. For PNC, three components of the services were measured: learnt about post-delivery complications among women and children, learnt about nutrition, anaemia and breast feeding, and received immunisation. These components of services were selected based on the guidelines and policy documents for ANC, delivery care and $\mathrm{PNC},{ }^{345-47}$ related literature ${ }^{48-54}$ and comments from health administrators at the study site. The services measured as listed above were limited to those that could be determined through women's self-reports.

This study collected the socioeconomic characteristics of women and their households that were likely to affect their MNCH service-seeking behaviour based on previous research. ${ }^{55-58}$ These characteristics included the women's ages, educational attainment, marital status, religion, number of pregnancies, age and educational attainment of their partners and number of children aged under 5 years in the household. Socioeconomic status was also estimated using factor analysis based on the following variables: availability of electric power, availability of a clean toilet, type of roof material of the house, ownership of refrigerator, availability of clean water, ownership of TV, ownership of radio, ownership of mobile phone and ownership of transportation (car and motorbike).

Factors during the latest pregnancy of women were also measured. These factors included intended pregnancy, birth preparedness, health insurance, support from household members and complications and danger signs.

\section{Data collection}

This study collected data using a structured questionnaire that was written in English. Interviewers who could speak at least one local language in a survey area were hired and received training in July 2013 on the objectives, design and ethical consideration of this study, as well as the contents of the questionnaire. Pretesting was undertaken in each HRC in July 2013, and the contents of the questionnaire were confirmed. Face-to-face interviews with women were undertaken from July to September 2013 in local languages that women could listen to and speak. The data items used to construct the socioeconomic status were extracted from the health demographic surveillance database at each HRC.

\section{Data analysis}

First of all, women whose information was partly missing or they were found not to meet the inclusion criteria were excluded from analysis. Then, descriptive analysis was performed to present the background characteristics of women and children in the sample and the coverage of CoC. Paired t-test was performed to compare the coverage in $\mathrm{MNCH}$ services using the definitions of visit-based $\mathrm{CoC}$ 
and services-based CoC. A multilevel logistic regression with a random intercept at the area level was performed to identify the factors associated with the achievement of $\mathrm{CoC}$ and the variance of the achievement across areas. In the regression, both of visit-based $\mathrm{CoC}$ and services-based $\mathrm{CoC}$ were dichotomised so that this study could evaluate factors associated with making all necessary visits to health facilities (visit-based $\mathrm{CoC}$ ) and received all necessary components of MNCH services (services-based CoC) as defined in the 'Measurements' section. As explanatory variables, socioeconomic characteristics (the women's ages, educational attainment, marital status, religion, number of pregnancies, age and educational attainment of their partners and number of children aged under 5 years in the household) and factors during the latest pregnancy of women (intended pregnancy, birth preparedness, health insurance, support from household members and complications and danger signs) were included in the model. Variance inflation factor was used to check the multicollinearity, although no variable exceeded 4 as a threshold. To evaluate to what extent differences in the level of CoC were caused by specific factors at the area level, this study used different sets of explanatory variables in the regression model. In addition to the full model (socioeconomic characteristics and factors relating to the latest pregnancy as explanatory variables), the null model (excluding all explanatory variables) and the model excluding factors relating to the latest pregnancy were tested. Then, intraclass correlation coefficient (ICC) was used to compare the proportion of variance caused by the random intercept at the area level among different models.

\section{Ethical consideration}

All respondents voluntarily participated and were given details of the study before the survey. Written informed consent was obtained, and confidentiality was assured for all participants.

\section{RESULTS}

\section{Characteristics of women and their households}

Table 1 shows the socioeconomic characteristics of women and their households. Of 1500 participants recruited, 99 women were excluded as their background information was partly missing or they were found not to meet the inclusion criteria. A sample of 1401 women was used in this study. Most women (84.6\%) were aged between 20 and 39 years. Only $9.0 \%$ of women were aged 19 years or under and $6.4 \%$ of women were aged 40 years or above. While $38.3 \%$ of women did not complete primary education, $23.3 \%$ and $28.6 \%$ of women completed primary and lower secondary education, respectively.

Table 1 also shows factors during the latest pregnancies of women. While $79.7 \%$ of women received non-financial support from their household members during and after deliveries, only $34.9 \%$ had prepared funds in advance for delivery. About half of the women (53.8\%) experienced complications during pregnancy, delivery or post-delivery
Table 1 Characteristics of women and households $(n=1401)$

n $\quad \%$

Socioeconomic characteristics

Age (years)

\begin{tabular}{|lrr|}
\hline$\geq 19$ & 126 & 9.0 \\
\hline $20-29$ & 708 & 50.5 \\
\hline $30-39$ & 477 & 34.1 \\
\hline$\leq 40$ & 90 & 6.4 \\
\hline Education & & \\
\hline None & 536 & 38.3 \\
\hline Primary & 327 & 23.3 \\
\hline Lower secondary & 401 & 28.6 \\
\hline Higher secondary or above & 137 & 9.8 \\
\hline Religion & & \\
\hline Christian & 733 & 52.3 \\
\hline Muslim & 198 & 14.1 \\
\hline Traditional and others & 412 & 29.4 \\
\hline NA & 58 & 4.1 \\
\hline Number of pregnancies & & \\
\hline One & 376 & 26.8 \\
\hline Two & 318 & 22.7 \\
\hline Three & 273 & 19.5 \\
\hline Four or more & 434 & 31.0 \\
\hline Marital status & & \\
\hline Married & 856 & 61.1 \\
\hline Cohabitating & 363 & 25.9 \\
\hline $\begin{array}{l}\text { Unmarried, widowed, divorced or } \\
\text { separated }\end{array}$ & 182 & 13.0 \\
\hline Parner's age (yeas) & & \\
\hline
\end{tabular}

Partner's age (years)

\begin{tabular}{lcc}
$\geq 29$ & 289 & 20.6 \\
$30-39$ & 448 & 32.0 \\
$\leq 40$ & 259 & 18.5 \\
$\quad$ Unknown or NA & 405 & 28.9 \\
\hline $\begin{array}{l}\text { Partner's education } \\
\text { None }\end{array}$ & 402 & 28.7 \\
Primary & 187 & 13.4 \\
Lower secondary & 390 & 27.8 \\
\hline Upper secondary or above & 308 & 22.0 \\
Unknown or NA & 114 & 8.1 \\
$\begin{array}{l}\text { No. of children aged under } \\
\text { 5 years (mean and SD) }\end{array}$ & 1.9 & 1.5 \\
$\begin{array}{l}\text { Socioeconomic status score* } \\
\text { (mean and SD) }\end{array}$ & 0.0 & 1.0 \\
\hline
\end{tabular}

Factors about the latest pregnancy

Intended pregnancy

\begin{tabular}{lll} 
Intended & 816 & 58.2 \\
Mistimed & 452 & 32.3 \\
\hline & & Continued
\end{tabular}




\begin{tabular}{lcc}
\hline Table 1 Continued & & \\
\hline & $\mathbf{n}$ & $\%$ \\
\hline Unwanted & 133 & 9.5 \\
\hline Money prepared for delivery & & \\
Yes & 489 & 34.9 \\
No & 912 & 65.1 \\
Held health insurance card & & \\
Yes & 658 & 47.0 \\
No & 743 & 53.0 \\
\hline
\end{tabular}

Received support from family member during and after delivery

\begin{tabular}{ccc} 
Yes & 1116 & 79.7 \\
No & 285 & 20.3 \\
\multicolumn{2}{c}{$\begin{array}{c}\text { Any complications for women during pregnancy, delivery } \\
\text { or post-delivery within }\end{array}$ weeks of delivery } \\
Yes & 754 & 53.8 \\
No & 647 & 46.2 \\
Any complications for child within 6 weeks of delivery \\
Yes & 247 & 17.6 \\
No & 1154 & 82.4 \\
\hline
\end{tabular}

*Standardised z-score based on factor analysis using the following variables: availability of electric power, availability of clean toilet, house roof material, ownership of refrigerator, availability of clean water, ownership of TV, ownership of radio and ownership of mobile phone.

NA, not available.

within 6 weeks of delivery and $17.6 \%$ of children had complications within 6 weeks of delivery.

\section{CoC achievement}

Table 2 presents CoC achievement in MNCH. Only 111 women $(7.9 \%)$ achieved visit-based $\mathrm{CoC} ; 145$ women $(10.3 \%)$ achieved services-based CoC.

\section{Coverage of MNCH services components}

The coverage of the key components in the $\mathrm{MNCH}$ services was substantially different from the coverage of the ANC, delivery attended by SBA or PNC. According to figure 1(A), $86.2 \%$ of women received ANC four times or more, and almost all women $(98.5 \%)$ visited the ANC at least once. Among the key components of the services, the coverage of the HIV test was lowest $(62.8 \%)$.

Figure 1(B) presents the differences between delivery assisted by SBA and the coverage of key components of services at delivery. The percentages of women who exercised skin-to-skin care and initiated breast feeding within an hour of delivery were $46.8 \%$ and $51.3 \%$, respectively. Such coverage was substantially lower than the rate of delivery at a health facility (75.8\%).

Figure 1(C) presents the coverage of PNC. Of all women, $25.5 \%$ received PNC for their children within 48 hours of delivery, while $92.0 \%$ received PNC around 6 weeks post-delivery. Women who learnt about complications, received treatment for anaemia and instruction on nutrition and received necessary immunisations were $49.0 \%, 60.5 \%$ and $62.7 \%$, respectively.

\section{CoC achievement across areas}

Figure 2 presents $\mathrm{CoC}$ achievement by area. According to figure 2(A), only one area out of 22 (area no. 15) exceeded 20\% regarding CoC visit-based achievement. Six areas did not have women who achieved CoC (area no. 7, 10, 11, 12, 17 and 21). Figure 2(B) shows that seven areas had no women who achieved CoC based on services received (area no. 7, 8, 10, 11, 17, 19 and 20), while four areas had a coverage of approximately $30 \%$ (area no. 2, 6,21 and 22).

\section{Multilevel logistic regression analysis of the factors associated with the CoC achievement}

Table 3 presents the result of the multilevel logistic regression analysis with a random intercept at the area

Table 2 CoC achievement in MNCH based on different measurements $(n=1401)$

\begin{tabular}{|c|c|c|c|c|c|c|c|c|}
\hline \multirow[b]{2}{*}{ ANC } & \multirow[b]{2}{*}{ Delivery } & \multirow[b]{2}{*}{ PNC } & \multicolumn{2}{|c|}{ Visit-based CoC } & \multicolumn{2}{|c|}{ Services-based CoC } & \multicolumn{2}{|c|}{$\begin{array}{l}\text { Visit-based and services } \\
\text { based CoC }\end{array}$} \\
\hline & & & $\mathbf{n}$ & $\%$ & $\mathbf{n}$ & $\%$ & $\mathbf{n}$ & $\%$ \\
\hline \multicolumn{9}{|c|}{ Achieved CoC } \\
\hline Yes & Yes & Yes & 111 & 7.9 & 145 & 10.3 & 25 & 1.8 \\
\hline \multicolumn{9}{|c|}{ Partially achieved CoC } \\
\hline Yes & Yes & No & 847 & 60.5 & 59 & 4.2 & 164 & 11.7 \\
\hline Yes & No & Yes & 28 & 2.0 & 257 & 18.3 & 29 & 2.1 \\
\hline Yes & No & No & 221 & 15.8 & 202 & 14.4 & 356 & 25.4 \\
\hline No & Yes & Yes & 8 & 0.6 & 75 & 5.4 & 20 & 1.4 \\
\hline No & Yes & No & 96 & 6.9 & 85 & 6.1 & 157 & 11.2 \\
\hline No & No & Yes & 4 & 0.3 & 181 & 12.9 & 41 & 2.9 \\
\hline \multicolumn{9}{|c|}{ Not achieved CoC } \\
\hline No & No & No & 86 & 6.1 & 397 & 28.3 & 609 & 43.5 \\
\hline
\end{tabular}

ANC, antenatal care; $\mathrm{CoC}$, continuum of care; $\mathrm{MNCH}$, maternal, newborn and child health; PNC, postnatal care. 


\section{CoC Measurement 1: visit-based CoC}

\section{A During ANC}

1. Received ANC 4 times or more

2. Received ANC at least once

CoC Measurement 2: services-based CoC

3. Completed all of 4-6

4. Received tetanus toxoid immunization

5. Received intermittent preventative treatment

6. Received HIV test

CoC Measurement 1 and 2

7. Completed 1 and 3

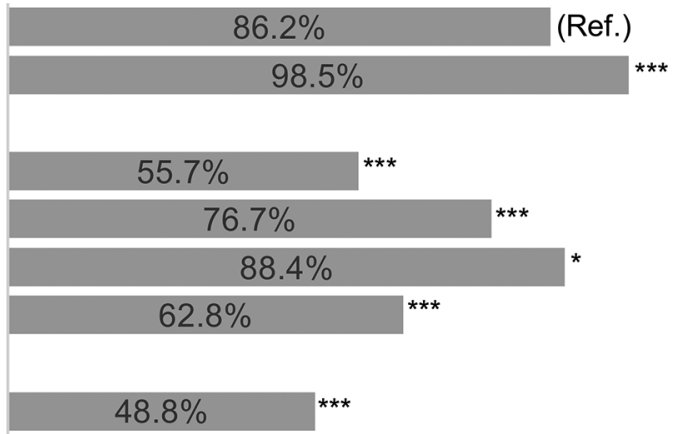

CoC Measurement 1: visit-based CoC

\section{B During delivery}

1. Delivered at health facility

2. Assisted by health worker

3. Completed 1 and 2

CoC Measurement 2: services-based CoC

4. Completed 5 and 6

5. Exercised skin-to-skin care

6. Initiated breastfeeding within an hour after delivery

CoC Measurement 1 and 2

7. Completed 3 and 4

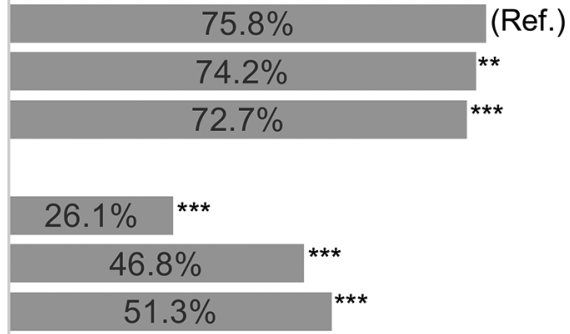

CoC Measurement 1: visit-based CoC

\section{During PNC}

1. Received all of $3,4,5$, and 6

2. Received at least one of $3,4,5$, or 6

3. Received PNC for mother

4. Received PNC for infant (within 48 hours)

5. Received PNC for infant (around 2 weeks)

6. Received PNC for infant (around 6 weeks)

CoC Measurement 2: services-based CoC

7. Completed all of 8-10

8. Learned about complications

9. Received anaemia treatment and instruction

10. Received necessary immunization

\section{CoC Measurement 1 and 2}

\section{Completed 1 and $7 \quad 8.2 \%{ }^{* * *}$ \\ $0 \% \quad 20 \% \quad 40 \% \quad 60 \% \quad 80 \% \quad 100 \%$}

Figure $1 \mathrm{MNCH}$ services received. (A) During ANC. (B) During delivery. (C) During PNC. Paired t-test was conducted for testing the difference in proportions between the reference variable and each of the other variables in each figure. ${ }^{*}$ Significant at $5 \%$ level; ${ }^{* \star}$ significant at $1 \%$ level; ${ }^{* * *}$ significant at $0.1 \%$ level. ANC, antenatal care; CoC, continuum of care; MNCH, maternal, newborn and child health; PNC, postnatal care; Ref., reference variable.

level regarding the factors associated with CoC achievement. According to model (3), religion, marital status and socioeconomic status were associated with better visit-based $\mathrm{CoC}$ achievement. Women who practised traditional religions or others were more likely to achieve CoC (adjusted OR (AOR) 2.71, 95\% CI 1.37 to 5.35), as compared with Christians. Women cohabitating with their partners without formal marriage were less likely to achieve CoC (AOR $0.49,95 \%$ CI 0.25 to 0.97 ), as compared with married women. Wealthier women were more likely to achieve CoC (AOR 1.50, 95\% CI 1.09 to 2.07).

According to model (6), services-based CoC achievement was explained by educational attainment, religion, 

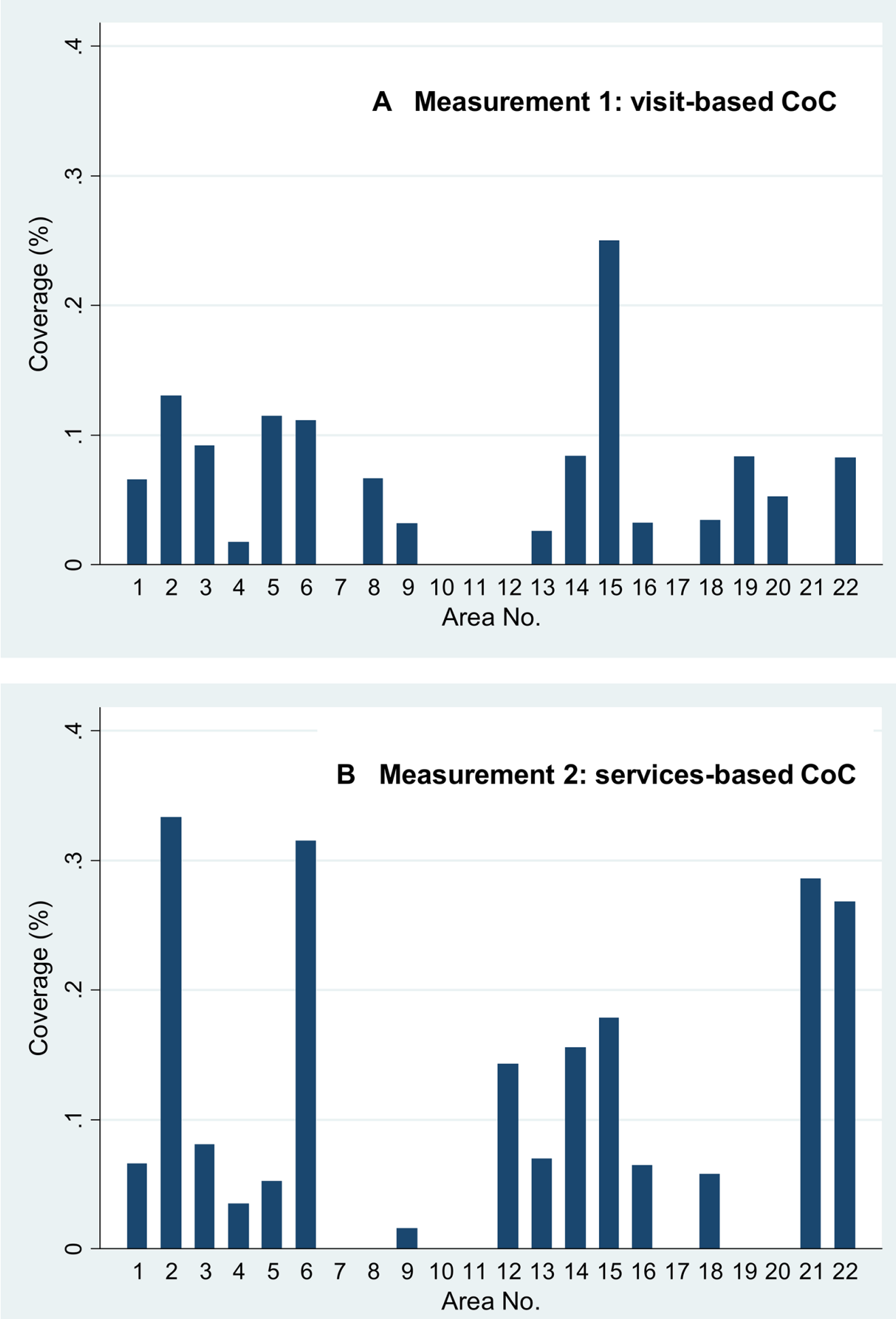

Figure 2 Continuum of care $(\mathrm{CoC})$ acheivement by measurement and area. (A) The percentage of women who achieved visitbased $\mathrm{CoC}$ exceeded $20 \%$ in one area out of 22 (area no. 15). Six areas did not have women who achieved visit-based CoC (area no. 7, 10, 11, 12, 17 and 21). (B) The percentage of women who achieved services-based CoC was approximately $30 \%$ in four areas (area no. 2, 6, 21 and 22). Seven areas had no women who achieved services-based CoC (area no. 7, 8, 10, 11, 17, 19 and 20).

socioeconomic status, financial preparedness and complications among women. Completed upper secondary education or above was positively associated with CoC achievement (AOR 2.47, 95\% CI 1.19 to 5.14), as compared with women without formal education. Women who practised traditional religions or others were more likely to achieve CoC (AOR 2.64, 95\% CI 1.40 to 5.00), as compared with Christians. Wealthier women were more likely to achieve CoC (AOR 1.41, 95\% CI 1.05 to 1.89). Women who prepared money for delivery were more 


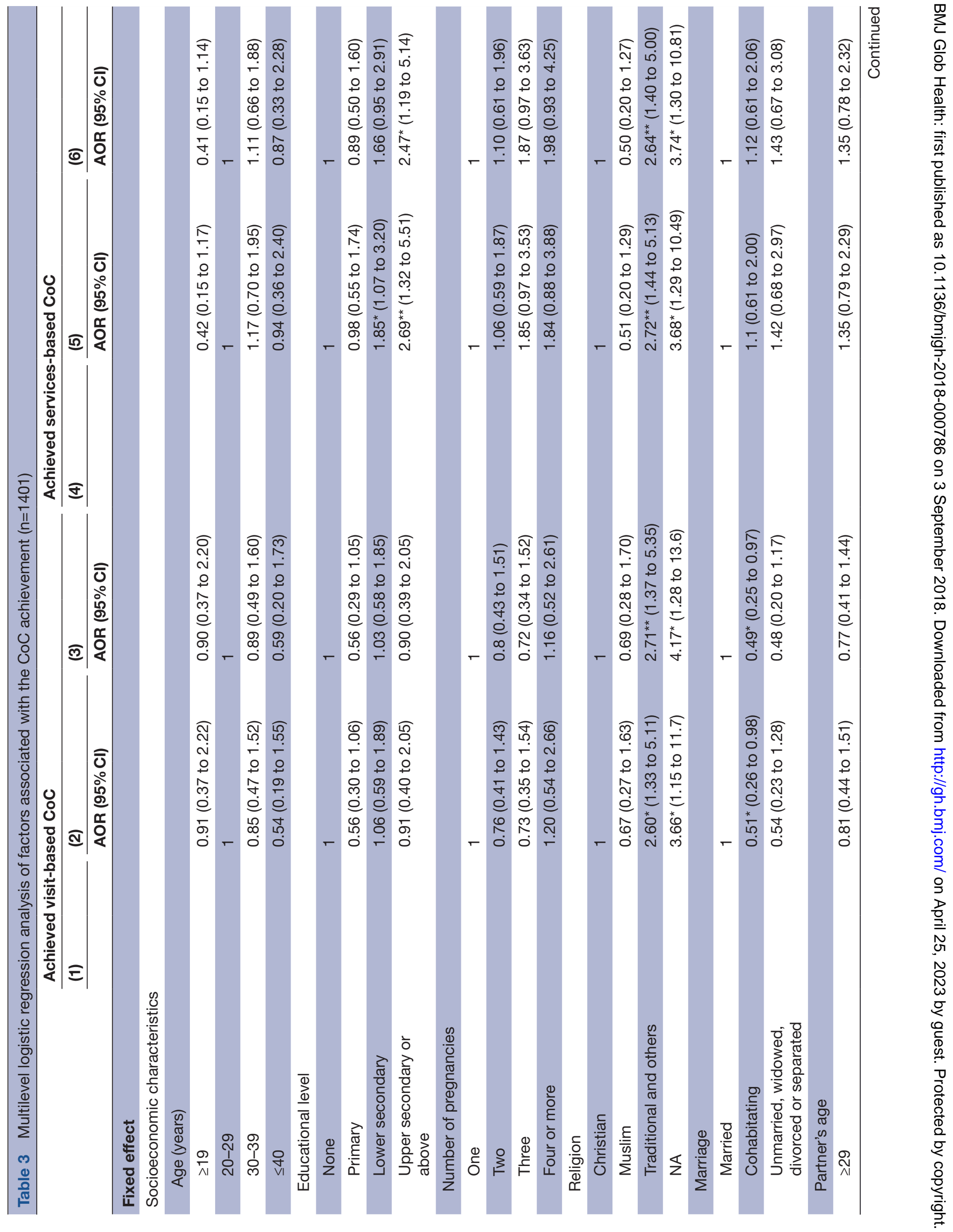




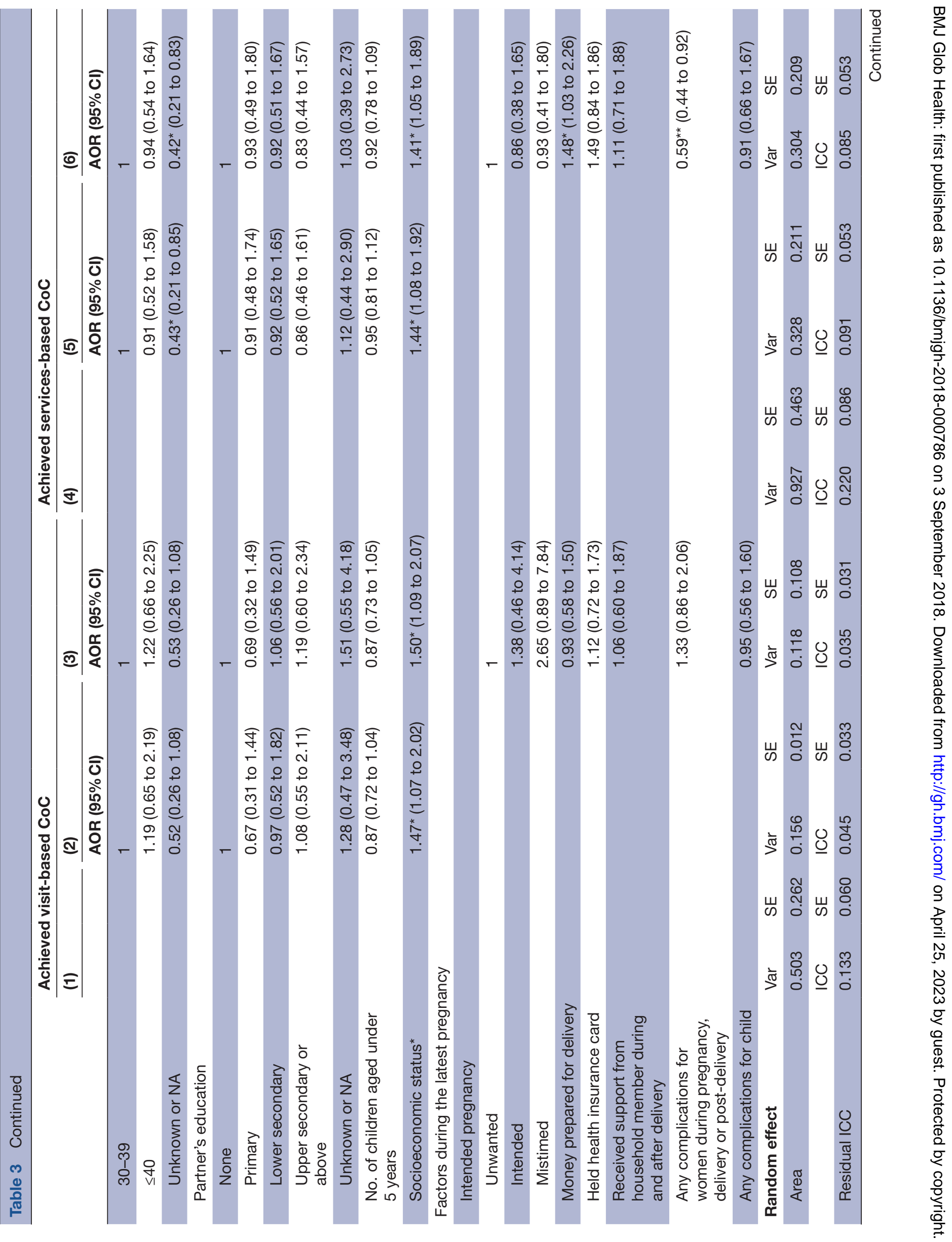


likely to achieve CoC (AOR 1.48, 95\% CI 1.03 to 2.26). Women who experienced any complications during pregnancy, delivery or post-delivery were less likely to achieve CoC (AOR 0.59, 95\% CI 0.44 to 0.92). Models (2) and (4) show that AOR and its level of significance for socioeconomic characteristics variables were not largely affected when excluding variables about factors during the latest pregnancy.

Table 3 also presents the proportion of variances caused by differences in CoC achievement across areas. According to the ICC in model (1), the null model, $13.3 \%$ of the variance regarding CoC visit-based achievement was explained by a random intercept, that is, areas in the place of living. After controlling for various factors related to women and their households, $3.5 \%$ of variations were explained by a random intercept according to model (3).

The variation in $\mathrm{CoC}$ achievement was larger when it was measured as services received. The ICC was $22.0 \%$ in the null model (model (4)) and $8.5 \%$ with explanatory variables (model (6)). The ICC of model (6) that estimated CoC services-based achievement received was more than twice as large as the ICC of model (3) for CoC visit-based achievement.

\section{DISCUSSION}

This study provides us with new insights on CoC achievement in $\mathrm{MNCH}$ at the time dimension in three HRCs in Ghana. First, most mothers and children did not receive $\mathrm{MNCH}$ services comprehensively during the pregnancy, delivery and post-delivery stages; visit-based and services-based achievement of CoC was low. Second, different factors were associated with CoC based on its two measurements. Women practising traditional religions and those with a formal marital status tended more towards making routine visits at facilities to achieve CoC. Women's education, financial preparedness and pregnancy complications among mothers were associated with services-based CoC. Women in wealthier households were more likely to achieve both visit-based and services-based CoC. Third, across-area differences were larger in services-based CoC than visit-based $\mathrm{CoC}$, after controlling for various factors related to women and their households.

In this study, a small percentage of women and children achieved CoC based on both measurements by visits and services received. The coverage of $\mathrm{CoC}$ was extensively lower than the coverage reported in the studies in Pakistan $(27 \%)$ and nine South Asian and sub-Saharan African countries (17\%) based on DHS. ${ }^{16} 17$ This can be explained as follows. First, CoC was interrupted by low coverage of PNC within 48 hours despite relatively high coverage of ANC and delivery attended by SBA. The coverage of PNC reported in this study was extensively lower than the widely cited PNC coverage based on DHS 2014 in Ghana (81\%). ${ }^{31}$ This is due to differences in measurement of PNC. The DHS measured PNC only once after delivery, and it regarded women who delivered 
at health facilities as having received PNC. However, delivery at a health facility does not guarantee that they received PNC as recommended. ${ }^{2728} 59$

Second, health facilities where women and children visited may not provide key components of $\mathrm{MNCH}$ services. In this study, the coverage of the key components of services in each of the pregnancy, delivery and post-delivery stages was largely lower than the coverage of ANC, delivery attended by SBA and PNC. This supports the view of an existing quality gap in the supply of MNCH services. $^{24} 25$

Different factors were associated with the coverage of both visit-based and services-based CoC. Notably, services-based CoC was affected by non-economic characteristics of women in addition to socioeconomic status. Such differences could be interpreted as follows. Providing the key components of services constitutes a portion of quality at a health facility. ${ }^{24}{ }^{27}$ Women could make a choice of which health facility to visit for MNCH services if they have access to two or more health facilities. In this case, they can achieve services-based CoC due to their proactive choice of better MNCH services. Educated women may be more capable of comparing the quality of $\mathrm{MNCH}$ services among candidate facilities. $^{3560}$

Socioeconomic status and religions were associated with better CoC achievement for both visits and services received. Poor socioeconomic status broadly explains the limited affordability of services, as is consistent with previous literature. ${ }^{55}$ 61-63 Women and children from poorer households had a lesser tendency to visit even the most easily accessed health facility. Mixed evidence exists in the effect of religion on $\mathrm{MNCH}$ service use. ${ }^{55}$ The effect of the same religion may be different across societies. In the study site, women had been advised to be at home after delivery. This can be interpreted as a factor that influenced the low coverage of PNC. However, it seems that women practising specific traditional beliefs were free from such traditions.

Across areas, variations in services-based CoC achievement were wider compared with visit-based $\mathrm{CoC}$ achievement. This implies that achieving visit-based CoC did not necessarily translate into services-based $\mathrm{CoC}$ and vice versa. In the multilevel models in table 3 , a random intercept might capture area-specific factors, after controlling for various factors specific to women and their households. Such area-specific factors may include differences in $\mathrm{MNCH}$ service provision. This is consistent with evidence found on the importance of the quality of $\mathrm{MNCH}$ service provision in its coverage in the previous literature. ${ }^{296465}$

This study highlighted the importance of monitoring $\mathrm{CoC}$ at the subnational level. According to the findings, the achievement of $\mathrm{CoC}$ was low on average and divergent across areas. Given the past progress of the coverage of ANC, delivery attended by SBA and PNC, a national $\mathrm{MNCH}$ policy should now address CoC by measuring to what extent women and children continuously receive services.
The measurements of visit-based and services-based CoC should be addressed in the national $\mathrm{MNCH}$ guideline in a country. This study counted PNC in the visit-based CoC as within 48 hours, 2 weeks and 6 weeks following the guideline in Ghana. The key components of services were selected from the guideline as well. In addition, the services-based CoC may be defined based on prioritisation in the national $\mathrm{MNCH}$ policy and data availability. For example, in Ghana, an $\mathrm{MNCH}$ policy document addresses the importance of $\mathrm{CoC}$ and prioritises key components of services to be provided during pregnancy, delivery, neonatal and childhood periods, although it does not define how to measure the achievement of CoC. ${ }^{66}$ Thus, the measurements of CoC can be different across countries as the measurements should serve the progress of MNCH services in line with the national MNCH guideline.

To solve divergence in CoC at the subnational levels, health administrators in a country can identify areas where CoC is low using the two measurements of CoC proposed in this study. Then, by comparing the two measurements, they may infer what factors broadly affected the low level of $\mathrm{CoC}$. If the visit-based $\mathrm{CoC}$ is relatively low in an area, then the availability of health facilities and factors related to women and their households, including socioeconomic and cultural factors, may be further investigated. In an area where the services-based $\mathrm{CoC}$ was relatively low, the provisions of services in health facilities may be constrained by supply-side factors. These factors include an excess in the number of clients and tasks relative to the number of health workers, the capacity and knowledge of health workers and insufficient equipment and supplies.

\section{Limitations}

This study has the following limitations. First, visits and received key components of services were measured based on women's answers obtained 6 weeks post-delivery or later. Despite potential recall bias, the authors believe that this is the best method to obtain information about $\mathrm{MNCH}$ service-seeking behaviours and the services received throughout different MNCH stages, including from women who did not visit health facilities or visited different health facilities during each visit. Second, geographic barriers to accessing a health facility, such as distance from a woman's residence to a health facility were not explicitly accounted for in this study, although differences in areas of residence were controlled under multilevel modelling. Third, some components of the $\mathrm{MNCH}$ services were excluded in this survey; this study measured only key components that could be ascertained through interviews with the women. Fourth, this study was implemented in three HRCs in Ghana and not nationally representative. The results of this study reflected the situations of CoC in the broader part of Ghana but not the whole country of Ghana.

\section{CONCLUSIONS}

In conclusion, this study highlights that most of women and children failed to achieve both visit-based and 
services-based CoC throughout the pregnancy, delivery and post-delivery stages. They did not necessarily achieve services-based CoC even if they achieved visit-based CoC. To ensure that every woman and child consistently receives the necessary care, both visit-based and services-based CoC should be enhanced. Particularly, MNCH services provision should be standardised so that women and children receive key components of services regardless of their area of living and a health facility that they visit.

\section{Author affiliations}

${ }^{1}$ Department of Community and Global Health, Graduate School of Medicine, The University of Tokyo, Tokyo, Japan

${ }^{2}$ Navrongo Health Research Centre, Navrongo, Ghana

${ }^{3}$ Kintampo Health Research Centre, Kintampo, Ghana

${ }^{4}$ Dodowa Health Research Centre, Dodowa, Ghana

${ }^{5}$ School of Public Health, University of Health and Allied Sciences, Ho, Ghana

${ }^{6}$ Research and Development Division, Ghana Health Service, Accra, Ghana

${ }^{7}$ Research and Education Center for Prevention of Global Infectious Diseases of

Animals, Tokyo University of Agriculture and Technology, Fuchu, Japan

${ }^{8}$ Institute for Health Research, University of Health and Allied Sciences, Ho, Ghana

Acknowledgements The authors would like to thank the Ministry of Foreign Affairs in Japan and the Ministry of Health in Ghana. The authors also express their gratitude to the Ghana Health Service and the District Health Management Teams of the Shai-Osudoku, Ningo-Prampram, Kintampo North, Kintampo South, Kassena Nankana East and Kassena Nankana West for the support they provided to this study. The Ghana EMBRACE Implementation Research Project was conducted by the Government of the Republic of Ghana, Japan International Cooperation Agency (JICA) Human Development Department and JICA Research Institute with a coordinating support from the System Science Consultancy.

Collaborators The Ghana EMBRACE Implementation Research Project Team. Yoshiharu Yoneyama; Ebenezer Appiah-Denkyira; Masamine Jimba; Abraham Hodgson; Gloria Quansah Asare; Evelyn Ansah; Junko Yasuoka; Keiko Nanishi; Akira Shibanuma; Kimiyo Kikuchi; Sumiyo Okawa; Margaret Gyapong; Sheila Addei; Vida Kukula; Doris Sarpong; Clement Narh; Seth Owusu-Agyei; Kwaku Poku-Asante; Charlotte Tawiah; Yeetey Enuameh; Kwame Adjei; Emmanuel Mahama; Abraham Oduro; John Williams; Cornelius Debpuur; Francis Yeji; Evelyn Sakeah; Peter Wontuo; Akiko Hagiwara; Sakiko Shiratori; Yusuke Kamiya.

Contributors AS conceived the research questions, designed the study, analysed the data and drafted the manuscript. FY and SO were involved in designing the study, conducting the fieldwork and revising the manuscript. EM, CTN and YE were involved in designing the study and conducting the fieldwork. KK and KN were involved in designing the study and revising the manuscript. EKA, AH and $\mathrm{MJ}$ monitored the study progress and were involved in revising the manuscript. All authors read and approved the final manuscript.

Funding This paper was funded by the Japan International Cooperation Agency (JICA) Human Development Department, and JICA Research Institute (https://www. jica.go.jp/english/index.html and https://www.jica.go.jp/jica-ri/).

Competing interests None declared.

Patient consent Not required.

Ethics approval Ethical approval was obtained from the Research Ethics Committee of the Graduate School of Medicine, the University of Tokyo, The Ethical Review Committee of the Ghana Health Service, Institutional Review Boards of Dodowa Health Research Centre, Kintampo Health Research Centre and Navrongo Health Research Centre.

Provenance and peer review Not commissioned; externally peer reviewed.

Data sharing statement There are no additional data available for this article.

Open access This is an open access article distributed in accordance with the Creative Commons Attribution Non Commercial (CC BY-NC 4.0) license, which permits others to distribute, remix, adapt, build upon this work non-commercially, and license their derivative works on different terms, provided the original work is properly cited, appropriate credit is given, any changes made indicated, and the use is non-commercial. See: http://creativecommons.org/ licenses/by-nc/4.0/.

\section{REFERENCES}

1. WHO, UNICEF, UNFPA, the World Bank, the United Nations Population Division. Trends in maternal mortality: 1990 to 2015. Geneva, Switzerland: World Health Organization, 2015.

2. The United Nations Inter-agency Group for Child Mortality Estimation. Levels and trends in child mortality report 2015. New York, USA: United Nations Children's Fund, 2015.

3. The Partnership for Maternal, Newborn \& Child Health. A global review of the key interventions related to reproductive, maternal, newborn and child health (RMNCH). Geneva, Switzerland: $\mathrm{PMNCH}$, 2011.

4. Wall SN, Lee AC, Carlo W, et al. Reducing intrapartum-related neonatal deaths in low- and middle-income countries-what works? Semin Perinatol 2010;34:395-407.

5. Lawn JE, Kerber K, Enweronu-Laryea C, et al. 3.6 million neonatal deaths--what is progressing and what is not? Semin Perinatol 2010;34:371-86.

6. Bhutta ZA, Ali S, Cousens S, et al. Alma-Ata: Rebirth and Revision 6 Interventions to address maternal, newborn, and child survival: what difference can integrated primary health care strategies make? Lancet 2008;372:972-89.

7. Mangiaterra V, Mattero M, Dunkelberg E. Why and how to invest in neonatal health. Semin Fetal Neonatal Med 2006;11:37-47.

8. Bryce J, Arnold F, Blanc A, et al. Measuring coverage in $\mathrm{MNCH}$ : new findings, new strategies, and recommendations for action. PLoS Med 2013;10:e1001423.

9. Tinker A, ten Hoope-Bender P, Azfar S, et al. A continuum of care to save newborn lives. Lancet 2005;365:822-5.

10. Kerber KJ, de Graft-Johnson JE, Bhutta ZA, et al. Continuum of care for maternal, newborn, and child health: from slogan to service delivery. Lancet 2007;370:1358-69.

11. Moran AC, Kerber K, Sitrin D, et al. Measuring coverage in $\mathrm{MNCH}$ : indicators for global tracking of newborn care. PLoS Med 2013;10:e1001415.

12. World Health Organization. The world health report: 2005: Make every mother and child count. Geneva, Switzerland: World Health Organization, 2005.

13. Lawn JE, Tinker A, Munjanja SP, et al. Where is maternal and child health now? Lancet 2006;368:1474-7.

14. Bustreo F, Requejo JH, Merialdi M, et al. From safe motherhood, newborn, and child survival partnerships to the continuum of care and accountability: moving fast forward to 2015. Int J Gynaecol Obstet 2012;119 Suppl 1:S6-S8.

15. Yeji F, Shibanuma A, Oduro A, et al. Continuum of Care in a Maternal, Newborn and Child Health Program in Ghana: Low Completion Rate and Multiple Obstacle Factors. PLoS One 2015;10:e0142849.

16. Iqbal S, Maqsood S, Zakar R, et al. Continuum of care in maternal, newborn and child health in Pakistan: analysis of trends and determinants from 2006 to 2012. BMC Health Serv Res 2017;17:189.

17. Singh K, Story WT, Moran AC. Assessing the Continuum of Care Pathway for Maternal Health in South Asia and Sub-Saharan Africa. Matern Child Health J 2016;20:281-9.

18. Wehrmeister FC, Restrepo-Mendez MC, Franca GV, et al. Summary indices for monitoring universal coverage in maternal and child health care. Bull World Health Organ 2016;94:903-12.

19. UNICEF, WHO. Tracking progress towards universal coverage for women's, children's and adolescents' health: The 2017 report. Washinton DC: UNICEF and World Health Organization, 2017.

20. Kinney MV, Lawn JE, Kerber KJ. Save the Children US. Science in action: Saving the lives of Africa's mothers, newborns, and children. Cape Town, South Africa: African Science Academy Development Initiative, 2009.

21. Kyei NN, Chansa C, Gabrysch S. Quality of antenatal care in Zambia: a national assessment. BMC Pregnancy Childbirth 2012;12:151.

22. McDonagh M. Is antenatal care effective in reducing maternal morbidity and mortality? Health Policy Plan 1996;11:1-15.

23. Campbell OM, Graham WJ. Lancet Maternal Survival Series steering group. Strategies for reducing maternal mortality: getting on with what works. Lancet 2006;368:1284-99.

24. Hodgins S, D'Agostino A. The quality-coverage gap in antenatal care: toward better measurement of effective coverage. Glob Health Sci Pract 2014;2:173-81.

25. Kinney MV, Kerber KJ, Black RE, et al. Sub-Saharan Africa's mothers, newborns, and children: where and why do they die? PLoS Med 2010;7:e1000294.

26. Graham WJ, Bell JS, Bullough $\mathrm{CH}$. Can skilled attendance at delivery reduce maternal mortality in developing countries. In: Van Lerberghe W, Kegels G, Brouwere D V, eds. Safe motherhood strategies: A review of the evidence. Antwerp: ITGPress, 2001:97-130. 
27. Nesbitt RC, Lohela TJ, Manu A, et al. Quality along the continuum: a health facility assessment of intrapartum and postnatal care in Ghana. PLoS One 2013;8:e81089.

28. Sines E, Syed U, Wall S, et al; Postnatal care: A critical opportunity to save mothers and newborns. Policy Perspectives on Newborn Health. Washington, DC: Population Reference Bureau, 2007

29. Jacobs B, Ir P, Bigdeli M, et al. Addressing access barriers to health services: an analytical framework for selecting appropriate interventions in low-income Asian countries. Health Policy Plan 2012;27:288-300.

30. Wang W, Hong R. Levels and determinants of continuum of care for maternal and newborn health in Cambodia-evidence from a population-based survey. BMC Pregnancy Childbirth 2015;15:62.

31. Ghana Statistical Service (GSS), Ghana Health Service (GHS), ICF Macro. Ghana demographic and health survey 2008. Accra, Ghana: GSS, GHS, and ICF Macro, 2009.

32. United Nations Development Programme. Beyond the midpoint: Achieving the Millennium Development Goals. New York, NY: United Nations Development Programme, 2010.

33. Kayode GA, Ansah E, Agyepong IA, et al. Individual and community determinants of neonatal mortality in Ghana: a multilevel analysis. BMC Pregnancy Childbirth 2014;14:165.

34. UNICEF, World Health Organization. Countdown to 2015 maternal, newborn \& child survival: Fulfilling the health agenda for women and children: The 2014 report. Geneva, Switzerland: World Health Organization, 2014

35. Naariyong S, Poudel KC, Rahman M, et al. Quality of antenatal care services in the Birim North District of Ghana: contribution of the community-based health planning and services program. Matern Child Health J 2012;16:1709-17.

36. Ntsua S, Tapsoba P, Asare GQ, et al; Repositioning communitybased family planning in Ghana: A case study of Communitybased Health Planning and Services (CHPS. Washington, DC: The Population Council, 2012.

37. Witter S, Adjei S, Armar-Klemesu M, et al. Providing free maternal health care: ten lessons from an evaluation of the national delivery exemption policy in Ghana. Glob Health Action 2009;2:1881.

38. Nyonator FK, Awoonor-Williams JK, Phillips JF, et al. The Ghana community-based health planning and services initiative for scaling up service delivery innovation. Health Policy Plan 2005;20:25-34.

39. Gyapong M, Sarpong D, Awini E, et al. Profile: the Dodowa HDSS. Int J Epidemiol 2013;42:1686-96.

40. Owusu-Agyei S, Nettey OE, Zandoh C, et al. Demographic patterns and trends in Central Ghana: baseline indicators from the Kintampo Health and Demographic Surveillance System. Glob Health Action 2012;5:19033-11.

41. Oduro AR, Wak G, Azongo D, et al. Profile of the Navrongo Health and Demographic Surveillance System. Int J Epidemiol 2012;41:968-76.

42. Kikuchi K, Ansah E, Okawa S, et al. Ghana's Ensure Mothers and Babies Regular Access to Care (EMBRACE) program: study protocol for a cluster randomized controlled trial. Trials 2015;16:22.

43. Okada K. Japan's new global health policy: 2011-2015. Lancet 2010;376:938-40

44. Takahashi K, Kobayashi J, Nomura-Baba M, et al. Can Japan Contribute to the Post Millennium Development Goals? Making Human Security Mainstream through the TICAD Process. Trop Med Health 2013;41:135-42.

45. World Health Organization. Guidelines on maternal, newborn, child and adolescent health approved by the WHO guidelines review committee: Recommendations on maternal and perinatal health. Geneva, Switzerland: World Health Organization, 2013.
46. United Nations Children's Fund. Committing to child survival: $A$ promise renewed. New York, NY, USA: United Nations Children's Fund, 2014.

47. World Health Organization. Pregnancy, childbirth, postpartum, and newborn care: A guide for essential practice. Geneva, Switzerland: World Health Organization, 2006.

48. Carroli G, Villar J, Piaggio G, et al. WHO systematic review of randomised controlled trials of routine antenatal care. Lancet 2001;357:1565-70.

49. World Health Organization. WHO antenatal care randomized trial: Manual for the implementation of the new model. Geneva Switzerland: World Health Organization, 2002.

50. Singh K, Brodish P, Haney E. Postnatal care by provider type and neonatal death in sub-Saharan Africa: a multilevel analysis. BMC Public Health 2014;14:941.

51. Villar J, Ba'aqeel H, Piaggio G, et al. WHO antenatal care randomised trial for the evaluation of a new model of routine antenatal care. Lancet 2001;357:1551-64.

52. Pallikadavath S, Foss M, Stones RW. Antenatal care: provision and inequality in rural north India. Soc Sci Med 2004;59:1147-58.

53. Shaw E, Levitt C, Wong S, et al. Systematic review of the literature on postpartum care: effectiveness of postpartum support to improve maternal parenting, mental health, quality of life, and physical health. Birth 2006;33:210-20.

54. Adegoke AA, van den Broek N. Skilled birth attendance-lessons learnt. BJOG 2009;116 Suppl 1(s1):33-40.

55. Simkhada B, Teijlingen ER, Porter M, et al. Factors affecting the utilization of antenatal care in developing countries: systematic review of the literature. J Adv Nurs 2008;61:244-60.

56. Mekonnen $Y$, Mekonnen A. Factors influencing the use of maternal healthcare services in Ethiopia. $J$ Health Popul Nutr 2003;21:374-82.

57. Mpembeni RN, Killewo JZ, Leshabari MT, et al. Use pattern of maternal health services and determinants of skilled care during delivery in Southern Tanzania: implications for achievement of MDG5 targets. BMC Pregnancy Childbirth 2007;7:29.

58. Babalola S, Fatusi A. Determinants of use of maternal health services in Nigeria--looking beyond individual and household factors. BMC Pregnancy Childbirth 2009;9:43.

59. Nair M, Yoshida S, Lambrechts T, et al. Facilitators and barriers to quality of care in maternal, newborn and child health: a global situational analysis through metareview. BMJ Open 2014;4:e004749.

60. Celik Y, Hotchkiss DR. The socio-economic determinants of maternal health care utilization in Turkey. Soc Sci Med 2000;50:1797-806

61. Gabrysch S, Campbell OM. Still too far to walk: literature review of the determinants of delivery service use. BMC Pregnancy Childbirth 2009;9:34.

62. Titaley CR, Dibley MJ, Roberts CL. Factors associated with nonutilisation of postnatal care services in Indonesia. J Epidemiol Community Health 2009;63:827-31.

63. Khanal V, Adhikari M, Karkee R, et al. Factors associated with the utilisation of postnatal care services among the mothers of Nepal: analysis of Nepal demographic and health survey 2011. BMC Womens Health 2014;14:19.

64. Ensor T, Cooper S. Overcoming barriers to health service access: influencing the demand side. Health Policy Plan 2004;19:69-79.

65. Thaddeus S, Maine D. Too far to walk: maternal mortality in context. Soc Sci Med 1994;38:1091-110.

66. Ministry of Health. Under five's child health policy: 2007-2015. Accra, Ghana: Ministry of Health, 2007. 